\title{
Duyu Eğitimi Programı'nın Korunma ve Bakım Altındaki Bebeklerin Motor Gelişimine Etkisinin İncelenmesi
}

\section{The Effect of Sensory Education Program on Infant Motor Development Who in Needs of Protection}

\author{
Duygu AKAGÜNDÜZ**, Ayşe Belgin AKSOY***
}

\begin{abstract}
Öz: Bu araştırma, devlet koruması altında olan bebeklerin motor gelişimine “Duyu Eğitimi Programı"nın etkisini incelenmek amacıyla yapılmıştır. Araştırmada genel tarama modellerinden, tekil tarama modeli kullanılmış olup, bir deneysel tarama deseni olan tek gruplu ön test-son test deseni uygulanmıştır. Çalışma grubu, Aile, Çalışma ve Sosyal Hizmetler İzmir İl Müdürlüğüne bağlı Çocuk Evleri Sitesi'nde kalan, 3-6 aylık, 12 bebekten oluşmaktadır. Çalışma grubundaki bebeklere haftada üç gün olmak üzere on iki hafta boyunca "Duyu Eğitimi Programı" uygulanmıştır. Araştırmada, bebeklere ilişkin genel bilgileri toplamak amacı ile Kişisel Bilgi Formu, "Duyu Eğitimi Programının" etkisini değerlendirmek amacı ile de Denver II Gelişimsel Tarama Testi kullanılmışıtır. Duyu Eğitimi Programı uygulaması kapsamında yapılan değerlendirmeler ile bebeklerin gelişimsel ilerleme durumu değerlendirilmiş ve sonuçlar tablo ve grafiklerle ortaya konmuştur. Ayrıca, elde edilen verileri analiz etmek için SPSS 20 paket programı kullanılmış ve verilerin normal dağılım göstermediği saptanmıştır. Wilcoxon İşaretli Sıralar Testi ile grup içi karşılaş̧ırmalar yapılıış ve sonuç olarak, ince ve kaba motor gelişim ön test ve son test ortalamaları arasında anlamlı bir fark olduğu $(\mathrm{p}<0.05)$ saptanmıştır.
\end{abstract}

Anahtar Kelimeler: Duyu eğitimi, motor gelişim, korumaya muhtaç çocuk, kurum bakımı

\begin{abstract}
This research is carried on to analyze the effect of "Sensory Education Program" on motor development of infants in need of legal protection. In this research, single screening model which is one of general screening models is used. In addition, pre-test post-test design which is an experimental screening design is implemented. The target population of the study is composed of 12 infants at the age of 3-6 months who live in Child Homes attached to İzmir Provincial Directorate of Family, Labor and Social Services. The documents that provide data for the research are Personal Information Form and The Denver II Developmental Screening Test. In this research, after "Sensory Education Program" was implemented three times a week during twelve weeks for the target population of the study, The Denver II Developmental Screening Test was applied. By means of mid-term evaluations made within the scope of Sensory Education Program, developmental process of children is evaluated and the results are shown graphically. The Statistical Program for Social Sciences (SPSS 20) package program was used to analyze the gained data, and it is determined that the data doesn't follow normal distribution. Wilcoxon Signed-Ranks Test was used to make intra-group comparisons. As a result, it is confirmed that there is a significant difference $(\mathrm{p}<0.05)$ between the pre-test and post-test averages of fine and gross motor skills.

Keywords: Sensory education, motor development, infant in need of legal protection, institutional care
\end{abstract}

\section{Giriş}

Motor gelişim, bebeklik döneminde açıkça gözlenebilen gelişim alanlarındandır. Hareket yetenekleri, çocukların algısal gelişimini kolaylaştıran önemli bir etken olarak görülür. Algısal ve motor yeteneklerin gelişimi, algısal, motor ve bilişsel süreçlerin birbirleri ile etkileşiminin bütünüdür (Bayhan ve Artan, 2009, s. 169). Her istemli hareket algısal bir işlemdir. Bebekler her türlü uyaranı çeşitli duyu modelleri ile alırlar. Bu uyaranlara karşılık verirler; ancak bu karşılıklar kısıtlı olabilir, çünkü duyusal uyaran, depolanmış ve öğrenilmiş bilgi ile birleştirildiğinde, bebek için anlamlı hale gelir (Aral ve Yücelyiğit,

\footnotetext{
* Bu çalışma Gazi Üniversitesi Eğitim Bilimleri Fakültesi Çocuk Gelişimi ve Eğitimi Anabilim Dalı tezli yüksek lisans kapsamında bitirme tezi olarak hazırlanmış ve Uluslararası IV. Çocuk Gelişimi Kongresi'nde sözlü bildiri olarak yayımlanmıştır.

** Uzman Çocuk Gelişimci, Aile Çalışma ve Sosyal Hizmetler İzmir İl Müdürlüğü, e-posta: dygakagndz@ gmail.com, ORCID: 0000-0002-1545-4588

*** Prof. Dr., Gazi Üniversitesi Gazi Eğitim Fakültesi Okul Öncesi Eğitimi Anabilim Dalı, e-posta: aksoya@gazi.edu.tr, ORCID: 0000-0003-0918-2560
} 
2014, s. 155). Bebekler doğdukları andan itibaren hareket ederler, hareket yolu ile öğrenirler ve çevrelerinde olup biten her şeye ilgi duyarlar. Çocuğun hareket beceri bilgisi ne kadar fazla ise çevreyi keşfetmesi, öğrenmesi ve temel motor becerilerini geliştirmesi o kadar kolay olur. Çocuk, çevreyi keşfetmek için hareket becerileri ile birlikte duyusal sistemini de kullanır. Beyin gelişimi hareket çeşitliliğine bağlıdır. Bu bağlamda motor becerilerin gelişmesi ile erken çocukluk dönemindeki öğrenme arasında bir ilişki vardır (Krog, 2015).

Bebekler üzerine yapılan çalışmalarda, çevresel uyarıcıların ve bakım veren ile bebek arasındaki karşılıklı ilişki ve etkileşimin bebeğin gelişimine olumlu yönde katkı sağlayacağından bahsedilir (Berk, 2015). Ancak, bazen bebeğin bu birebir etkileşimden yoksun kaldığ1 zamanlar olabilir. Kurum bakımında kalan bebeklerle ilgili yapılan çalışmalar, genel olarak, uyarıcı bir çevrenin, psiko-sosyal gelişim için önemini vurgular oysa bebeklerin, zengin uyarıcıdan yoksun, nadiren konuşuldukları ve dokunuldukları mekanlarda günlerini geçirmeleri, algıda yetersizliklere de yol açabilir.

Araştırmalar, kurum bakımının insan gelişimi üzerinde bazı zararlı etkileri olduğunu öne sürse de, bu etkilerin niteliği ve miktarı belirsizdir. Kurum bakımının zarar verici etkilerinin nedenleri araştırmalara konu olmuş, bu konuda çalışan araştırmacılar bu nedenleri birincil bakıcı olan anneden ayrılmanın yarattığı güvensiz bağlanma ve yetersiz bilişsel uyarım şeklinde açıklamışlardır. Güvensiz bağlanma üzerinde çalışanlar, kurumların insan gelişimi üzerinde uzun süreli ve kalıcı zararlı etkileri olduğunu, yetersiz uyarım üzerinde çalışanlar ise kurumların insan gelişimini geri dönülmez biçimde etkilemediğini, etkilerin kısa süreli olduğunu ve erken müdahale ile bu etkilerin azalabileceğini savunmuşlardır (Sloutsky, 1997).

Kurum bakımı altındaki çocuklar, psiko-sosyal olarak dezavantajlılar grubunda olup, özel gereksinimi olan çocuklar içinde yer almaktadırlar. Kurum yaşantısı, çocuğun düşünce, fiziksel, motor, davranışsal, sosyal duygusal gelişimini olumsuz etkilemektedir (Turan ve İpek-Yükselen, 2015, s. 89). Bebeklik dönemini içeren yıllar bireyin tüm gelişim alanları açısından kritik öneme sahip olmakla birlikte bu dönemde bireye sunulan destek bireyin sahip olduğu kapasiteyi en üst düzeye çıkarmasına yardımcı olmaktadır. Ülkemizde bebeklik dönemi ile ilgili yapılan araştırma sayının ve kapsamının sınırlı olduğu, yapılan çalışmaların çoğunun yurtdışında ve ülkemizde olanların da tıp/sağlık alanına ait olduğu görülmektedir (Aksoy ve Koran, 2014).

Kurum çocukları ile yapılan çalışmaların, sonuçları hem normal gelişim hem anormal veya gecikmiş gelişim hem de sosyal hizmetler hakkında önemli bilgiler verir. Ayrıca kurum örnekleri yoksunluk ve mahrumiyetten sonraki gelişimsel süreçlerin değerlendirilmesine de izin verir. Kurumda kalan ve kalmayan çocuklar arasındaki farklılıkları açıklamak için firsat verir ve çocukların yaşadığı çevrenin davranışlarına ve gelişimlerine nasıl etki ettiği belirlenir (Maclean, 2003). Toplumsal olarak izole edilmiş ve kuruma yerleştirilmiş çocukların gelişim çalışmaları, sosyal çevrenin insan gelişim, üzerindeki etkisi için kanıtlar sunar (Sloutsky, 1997). Uyarıcı materyallerin veya oyuncakların çeşitliliğinin arttırılması, fiziki kullanım alanının kısıtlılı̆̆ının azaltılması kurumda kalan çocukların gelişimine katkı sağlar. Sosyal, bilişsel uyarım ve etkileşim için kurumlarda çocuklara sıcak, samimi, bakım verenlerle sürekli bir ilişki, sağlıklı bir gelişim için ön koşul olarak sunulması gerekir. Çocukyetişkin ilişkisinde algısal ve bilişsel deneyimler kurumlardaki çocukların tüm gelişim alanlarını doğrudan etkiler. Kurumlarda yeni beceriler edinme ya da uygulama için çok az firsatlar sunulur. İhtiyaca ya da bireysel farkl1lıklara çok az çeşitlilik ve uyum sağlanabilir. Çünkü toplu yaşamda uyulmasi gereken kurallar vardır (Morison, Ames, Chisholm ve Carter, 1995).

Kurumların çevresel olanaklarının güçlendirilmesi çocukların gelişimsel yeterlilikleri üzerinde anlamlı etkilere yol açacaktır (Turan ve İpek-Yükselen, 2015). Kurum bakımı altına alınmış korumaya muhtaç çocukların bireysel ilgi ve sevgi gereksinimlerinin karşılanabilir olması her alandaki gelişimlerinin desteklenmesi gerekmektedir. Mevcut sistem içerisinde toplumdaki bireylerin sosyal sorumluluk bilinci ile hareket ederek bu risk altındaki dezavantajlı gruplara yönelik destekleyici yollarla fayda sağlamak büyük önem taşımaktadır. Bu çalışmada bebekler kendi koşulları içerisinde değerlendirilerek onları destekleyici etkinliklerle motor gelişimlerine katkı sağlamak hedeflenmiştir. Bu araştırmada da temel olarak, çocuk evleri sitesi müdürlüğünde koruma ve bakım altında olan 3-6 aylık bebeklere uygulanan duyu eğitimi programının motor gelişimlerine etkisinin olup olmadığının incelenmesi amaçlanmıştır. Bu temel amaç doğrultusunda aşağıdaki alt amaçlara yanıt aranmıştır:

- Duyu eğitiminin bebeklerin kaba motor becerilerine olan etkisi nedir?

- Duyu eğitiminin bebeklerin ince motor becerilerine olan etkisi nedir?

- Korunma ve bakım altında olan 3-6 aylık bebeklerin motor becerileri ne düzeydedir? 


\section{Yöntem}

\section{Araştırmanın modeli}

Araştırmada genel tarama modellerinden, tekil tarama modeli kullanılmış olup, bir deneysel tarama deseni olan tek gruplu ön test-son test deseni uygulanmıştır. Bilimsel açıdan kuvvetli olan, iki gruplu yani deney ve kontrol grupları arasında ön test-son test deseni uygulamaktır (Büyüköztürk, 2004). Ancak bu araştırmada, kendi koşulları içerisinde değerlendirilip herhangi bir karşılaştırmaya maruz kalması istenmeyen, hali hazırda dezavantajlı kabul edilen, risk altındaki bir grupla çalışılacağ 1 ve etik olarak daha uygun olacağı düşünüldüğünden tek gruplu ön test- son test deseni tercih edilmiştir.

\section{Çalışma grubu}

$\mathrm{Bu}$ araştırma, İzmir Çocuk Evleri Sitesi Müdürlügü’nde korunma ve bakım altında bulunan ve yaşları 3-6 ay arasında değişen on iki bebek ile yürütülmüş̧ür. Çalışma grubu tanılı herhangi bir engeli veya hastalığı bulunmayan, sağlıklı bebeklerden oluşturulmuştur.

\section{Veri toplama araçları}

Denver II Gelişimsel Tarama Testi: 0-6 yaş çocuklarının gelişimini değerlendirmek için kullanılan bir testtir. Bu tarama testi, kişisel-sosyal, ince motor, kaba motor, dil olmak üzere dört bölümde toplanmış 134 maddeden oluşmaktadır. Testin uygulanmasına çocuğun yaşına uygun noktadan başlanmakta ve 'geçer', 'kalır', 'olanak dışı' ve 'reddetme' biçiminde ifadelerle puanlanmaktadır. Alınan puanlara göre bireyler 'normal', 'anormal', 'şüpheli' ve 'test edilemez' şeklinde yorumlanmaktadır (Yalaz, Anlar ve Bayoğlu, 2009).

$\mathrm{Bu}$ testin testörler tarafından uygulanabilir olması için testör adaylarına Gelişimsel Nöroloji Derneği tarafından eğitim verilmekte ve bu eğitim sonunda yapılan sınav sonucuna göre yeterlilik belgesi verilmektedir. Araştırmacının ilgili dernekten alınmış 12/85 sayılı yeterlilik belgesi bulunmaktadir.

Kişisel Bilgi Formu: Araştırmacı tarafından, araştırmaya konu olan bebekler hakkında daha ayrıntılı bilgi vermek amacıyla, yaş, cinsiyet, kardeş durumu, aile ziyaretlerinin olup olmadığ 1 ve kuruma geliş bilgilerini içeren konularda hazırlanmıştır ve form kurum çalışanlarından elde edilen bilgilerle göre doldurulmuştur.

\section{İşlem}

Bu çalışmada kullanılan duyu eğitimi programı 0-36 Aylık Gelişimi Risk Altındaki Çocuklar İçin Gelişim Destek Programı (GEDEP), 0-36 Ay Çocuklar İçin Eğitim Programı ile Bütünleştirilmiş Aile Destek Eğitim Rehberi (EBADER) ve 0-12 ay kaba ve ince motor gelişim göstergeleri temel alınarak hazırlanmıştır. Program, seçilen kazanım ve göstergeleri destekleyecek toplam yirmi beş etkinlikten oluşmaktadır. Etkinlikler oluşturulurken, kaynak olarak Milli Eğitim Bakanlığı'nın (MEB) hazırlamış olduğu 0-36 aylık bebeklere yönelik etkinliklere ek olarak, Aksoy ve Çifçi (2008), Ellison (2006), Featherstone ve Featherstone (2005), Young'ın (2010) ilgili yaş gruplarına yönelik etkinlik kitaplarından yararlanılmış, bebeklerin ilgisini çekmek için ise materyal kullanımına özen gösterilmiştir. Etkinliklerin süresi, bebeklerin etkinliği yapma motivasyonlarına göre değişiklik göstermiş olsa da ortalama her bebek için 10dk. zaman ayrılmıştır. Duyu eğitimi programındaki etkinliklerde, süngerler, kurdeleler, renkli kağıtlar, düğmeler, farklı dokuda ve renkte kumaşlar, gazete kağıtları, poşetler, ayna, çıngırak, zil vb. materyaller kullanılmıştır.

Programda "Görme, İşitme, Dokunma, Koklama, Tatma" duyu alanlarına ait etkinlikler hakkında "etkinlik alanı, etkinlik adı, amaçlar, süre, materyaller, öğrenme süreci (uygulama)" şeklinde detaylı bilgilere yer verilmiştir. Seçilen etkinlikler bebeklere on iki oturum olmak üzere hazırlanmış olup, her oturum haftada üç kez uygulanmıştır. Araştırmada, bebeklere ilişkin genel bilgileri toplamak amacı ile Kişisel Bilgi Formu, "Duyu Eğitimi Programının" etkisini değerlendirmek amacı ile de Denver II Gelişimsel Tarama Testi kullanılmıştır. Eğitime başlamadan önce çalışma grubunda yer alan bebeklerle program öncesinde tanışmak ve etkileşime girmek için ilk bir hafta gözlem amaçlı olarak bebeklere bakım veren personel ve grup sorumluları (öğretmen ve çocuk gelişimci) ile görüşmeler yapılmış, günlük yaşam programları gözlemlenmiştir. 
Toplam 3 ay süren programda bebeklere Denver II Gelişimsel Tarama Testi ile belirli aralıklarla dört gelişimsel değerlendirme yapılmıştır.

Eğitime başlamadan önce Denver Gelişimsel Tarama Testi ile bebeklerin uygulama öncesi var olan gelişim durumu belirlenmiş, eğitim verilmeye başlandiktan 1 . ay ve 2 . ay sonra izleme testleri yapılmış, 3. ayın sonunda bebeklerin uygulama sonrasındaki gelişim durumunu belirlemek için yeniden test yapılmıştır. Bebeklerin gelişim durumları tablolar halinde sunulmuştur.Programın içeriği ile ilgili çalışma takvimi Tablo 1'de verilmiştir.

Tablo 1.

Programın İçeriği

\begin{tabular}{|c|c|}
\hline 1.Hafta & $\begin{array}{l}\text { Tanışma, Gözlem, Kişisel Bilgi Formunun doldurulması ve Denver II } \\
\text { Gelişim Testinin uygulanması (ön test-1. değerlendirme) }\end{array}$ \\
\hline 2.Hafta: 1. Oturum & Etkinlik uygulamaları \\
\hline 3.Hafta: 2. Oturum & Etkinlik uygulamaları \\
\hline 4.Hafta: 3. Oturum & Etkinlik uygulamaları \\
\hline 5.Hafta: 4. Oturum & Etkinlik uygulamaları \\
\hline 6.Hafta: 1. Ay sonu & Denver II Gelişim Testinin uygulanması (2. değerlendirme) \\
\hline 7.Hafta: 5. Oturum & Etkinlik uygulamaları \\
\hline 8.Hafta: 6. Oturum & Etkinlik uygulamaları \\
\hline 9.Hafta: 7. Oturum & Etkinlik uygulamaları \\
\hline 10.Hafta: 8. Oturum & Etkinlik uygulamalar1 \\
\hline 11.Hafta: 2. Ay sonu & Denver II Gelişim Testinin uygulanması (3. değerlendirme) \\
\hline 12.Hafta: 9. Oturum & Etkinlik uygulamaları \\
\hline 13.Hafta: 10. Oturum & Etkinlik uygulamaları \\
\hline 14.Hafta: 11. Oturum & Etkinlik uygulamaları \\
\hline 15.Hafta: 12. Oturum & Etkinlik uygulamaları \\
\hline 16.Hafta: 3. Ay sonu & Denver II Gelişim Testinin uygulanması (4. değerlendirme) \\
\hline
\end{tabular}

\section{Verilerin analizi}

Çalışma grubundaki bebeklere, araştırmacı tarafından haftada üç gün olmak üzere on iki oturum "Duyu Eğitimi Programı" verilmiştir. Araştırmada, bebeklere ilişkin genel bilgileri toplamak amacı ile Kişisel Bilgi Formu, "Duyu Eğitimi Programının" etkisini değerlendirmek amacı ile de Denver II Gelişimsel Tarama Testi kullanılmıştır Elde edilen verileri analiz etmek için SPSS 20 paket programı kullanılmış, tek bir grup ve bu grup üzerinde yapılan iki ölçme söz konusu olduğu için ilişkili gruplarda nonparametrik bir yöntem olan Wilcoxon İşaretli Sıralar Testi kullanılmıştır.

\section{Bulgular ve Tartışma}

Duyu Eğitimi Programı boyunca, D2GTT ile yapılan dört gelişimsel değerlendirmenin sonucu Tablo 2'de verilmiştir.

Tablo 2.

Denver II Gelişimsel Tarama Testi Sonuçlarının Gelişim Alanlarına Göre Dağılımı

\begin{tabular}{clllll}
\hline & & $\begin{array}{l}\text { Normal } \\
\mathrm{n}(\%)\end{array}$ & $\begin{array}{l}\text { Şüpheli } \\
\mathrm{n}(\%)\end{array}$ & $\begin{array}{l}\text { Anormal } \\
\mathrm{n}(\%)\end{array}$ & $\begin{array}{l}\text { Toplam } \\
\mathrm{n}(\%)\end{array}$ \\
\hline & Kişisel-Sosyal & $11(91,6)$ & $1(8,4)$ & $0(0)$ & $12(100)$ \\
Ön Test & İnce Motor & $7(58,3)$ & $5(41,7)$ & $0(0)$ & $12(100)$ \\
(1.Değerlendirme) & Dil & $12(100)$ & $0(0)$ & $0(0)$ & $12(100)$ \\
& Kaba Motor & $8(66,6)$ & $4(33,4)$ & $0(0)$ & $12(100)$ \\
& Genel Sonuç & $6(50)$ & $6(50)$ & $0(0)$ & $12(100)$ \\
\hline & Kişisel-Sosyal & $12(100)$ & $0(0)$ & $0(0)$ & $12(100)$ \\
1. Ay & İnce Motor & $8(66,6)$ & $3(25)$ & $1(8,4)$ & $12(100)$ \\
(2.Değerlendirme) & Dil & $12(100)$ & $0(0)$ & $0(0)$ & $12(100)$ \\
& Kaba Motor & $12(100)$ & $0(0)$ & $0(0)$ & $12(100)$ \\
& Genel Sonuç & $8(66,6)$ & $3(25)$ & $1(8,4)$ & $12(100)$ \\
\hline
\end{tabular}


“Duyu Eğitimi Programı”nın Korunma ve Bakım Altındaki Bebeklerin Motor Gelişimine Etkisinin İncelenmesi

\begin{tabular}{clllll}
\hline & Kişisel-Sosyal & $12(100)$ & $0(0)$ & $0(0)$ & $12(100)$ \\
2. Ay & İnce Motor & $10(83,3)$ & $2(16,7)$ & $0(0)$ & $12(100)$ \\
(3.Değerlendirme) & Dil & $10(83,3)$ & $2(16,7)$ & $0(0)$ & $12(100)$ \\
& Kaba Motor & $11(91,6)$ & $1(8,4)$ & $0(0)$ & $12(100)$ \\
& Genel Sonuç & $9(75)$ & $5(41,6)$ & $0(0)$ & $12(100)$ \\
\hline & Kişisel-Sosyal & $12(100)$ & $0(0)$ & $0(0)$ & $12(100)$ \\
Son Test & İnce Motor & $12(100)$ & $0(0)$ & $0(0)$ & $12(100)$ \\
(4.Değerlendirme) & Dil & $11(91,6)$ & $1(8,4)$ & $0(0)$ & $12(100)$ \\
& Kaba Motor & $12(100)$ & $0(0)$ & $0(0)$ & $12(100)$ \\
& Genel Sonuç & $8(66,6)$ & $4(33,4)$ & $0(0)$ & $12(100)$ \\
\hline
\end{tabular}

Tablo 2 incelendiğinde, ön test (1. değerlendirme) sonuçlarına göre, kişisel-sosyal gelişim alanında bir şüpheli gelişim, ince motor gelişim alanında beş şüpheli gelişim, toplam altı şüpheli gelişime sahip bebek olduğu yani grubun \%50'sinin gelişiminin şüpheli bulunduğu görülmektedir. Bebeklere uygulanan duyu eğitimi programının 1. ayından sonra yapılan 2. değerlendirme sonuçlarına göre ise ince motor gelişim alanında üç şüpheli gelişim ve bir anormal gelişim saptandığı, diğer gelişim alanlarında şüpheli ya da anormal gelişim görülmediği, duyu eğitimi programının 2. ayından sonra yapılan 3. değerlendirme sonuçlarına göre ise ince motor gelişim alanında iki, dil gelişimi alanında iki, kaba motor gelişim alanında bir şüpheli gelişim gözlemlenmiş olup grubun \%41,6'sında şüpheli gelişime rastlanıldığı görülmektedir. Bebeklere uygulanan D2GTT son test (4. değerlendirme) sonuçlarına göre de dil gelişimi alanında 1 şüpheli gelişim görülmüş olup, kişisel sosyal, ince motor, kaba motor gelişim alanlarında gecikme görülmediği anlaşılmaktadır.

D2GTT puanlaması ve yorumlanmasında, bebeklerin yaş grubu dahilindeki maddeleri içeren becerilerde yeterlilik göstermesi beklenir. Buna göre bu çalışmada, bebeklerin kaba motor, ince motor ve kişisel sosyal gelişim alanlarında yapılan son değerlendirmede yaşından beklenen becerileri yerine getirebildikleri ancak on iki bebekten birinin, dil gelişiminde yaş grubu dahilindeki maddeleri içeren becerileri gerçekleştiremediği görülmektedir. Dil gelişimi alanındaki bu durum, alan yazındaki diğer çalışmalarda, araştırmacılar tarafından, kurumların yapısal özellikleri ile ilişkilendirilmiş̧ir. Kurumlarda görevli bakım personellerinin sürekli değişiklik gösteren vardiyalarla çalışması ve bu yüzden bebeklerin sabit kişiler yerine birçok bakım personeliyle karşılaşması kurumlarda yaygın olarak bulunan fakat olumsuz etkileri ortaya konan bir durumdur (Muhamedrahimov, Palmov, Nikiforova, Groark ve McCall, 2004). Bu çalışmada, 12 bebekten yalnızca birinin, dil gelişimi alanında D2GTT'ne göre yaş grubu dahilinde gerçekleştirmesi gereken maddeleri içeren becerileri gerçekleştiremediği, ancak diğer bebeklerin yeterli gelişim gösterdiği ve buna göre, yapılan çalışmanın, bebeklerin bütünsel gelişimine olumlu yönde etki ettiği söylenebilir. Tablo 3'de çalışma grubundaki 12 bebeğin D2GTT sonuçlarının ön test ve son test sonuçları verilmiştir.

Tablo 3.

Çalışma Grubunun Denver Gelişimsel Tarama Testi Motor Gelişim Ön Test- Son Test Puanlarına İlişkin Wilcoxon İşaretli Sıralar Testi Sonuçları

\begin{tabular}{ccccccr}
\hline & Sıra & N & Sıra Ort. & Sıra Toplam1 & $X^{2}$ & $\mathrm{p}$ \\
\hline \multirow{2}{*}{ İnce Motor Gelişim } & Negatif Sıra & 0 & 0,00 & 0,00 & 0,025 & 0,05 \\
Alanı & Pozitif Sıra & 5 & 3,00 & 15,00 & & \\
Ön Test-Son Test & Eşit & 7 & & & & \\
\hline Toplam & 12 & & & & \\
Kaba Motor & Negatif Sıra & 0 & 0,00 & 0,00 & 0,046 & 0,05 \\
Gelişim Alanı & Pozitif Sira & 4 & 2,50 & 10,00 & & \\
Ön Test-Son Test & Eşit & 8 & & & & \\
\hline
\end{tabular}

Tablo 3 incelendiğinde, ince ve kaba motor gelişim alanı ön test ve son test puan ortalamaları arasında anlamlı bir fark olduğu $(\mathrm{p}<0,05)$ yani duyu eğitimi programının bebeklerin motor gelişimi üzerinde etkili olduğu saptanmıştır. 
Şekil 1'de çalışma grubundaki 12 bebeğin D2GTT ön test ve son test sonuçlarından elde edilen gelişim grafiği verilmiştir. Şekil 1 incelendiğinde, D2GTT'ne göre yapılan son test değerlendirmesinde elde edilen normal gelişimin, ön test değerlendirmesinde elde edilen normal gelişimden daha fazla olduğu görülmektedir. D2GTT'ne göre yapılan son test değerlendirmesinde elde edilen şüpheli gelişimin ön test değerlendirmesinde elde edilen şüpheli gelişimden daha az olduğu görülmektedir. Ayrıca D2GTT'ne göre yapılan ön test ve son test değerlendirmelerinde motor gelişim alanında herhangi bir anormal gelişime rastlanmadığı görülmektedir. Bu doğrultuda duyu eğitimi programı uygulamaları sonucunda D2GTT'ne göre elde edilen şüpheli gelişimde bir azalma olduğu, normal gelişimde ise artma olduğu söylenebilir.

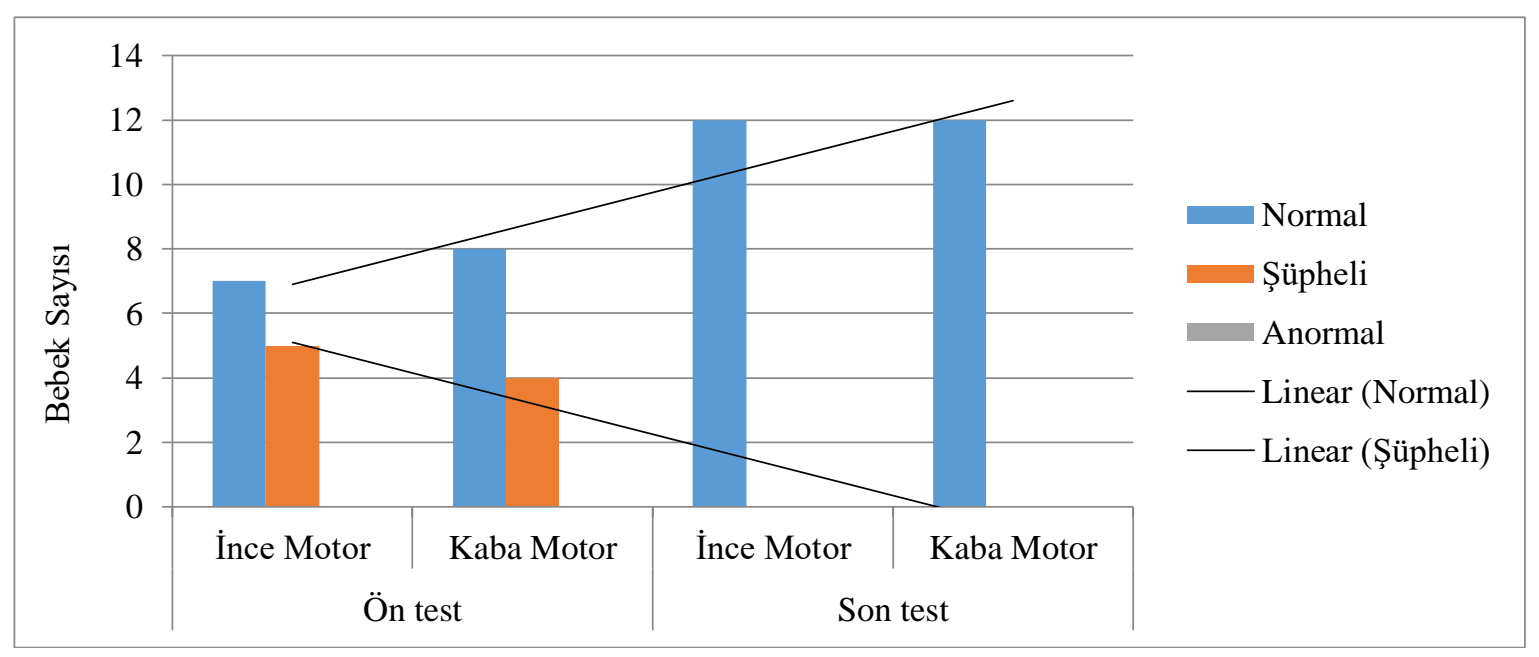

Şekil 1. Denver II Gelişimsel Tarama Testi ince motor ve kaba motor gelişim alanları ön test ve son test değerlendirme sonuçlarının karşılaştırılması

Araştırmalar göstermiştir ki eğer çocuklar motor yetenekleri öğrenmeye teşvik edilirse, motor yetenekler yaşlarına göre umulandan daha hızlı bir şekilde gelişme evresi geçirir. Motor gelişime müdahale etmek, motor gelişimi yalnızca hızlandırmakla kalmaz aynı zamanda olası gecikmeleri önler ve bilişsel gelişim başta olmak üzere diğer gelişim alanları da desteklenmiş olur. Yapılan birçok araştırmada, çevresel faktör olarak fiziksel aktiviteli uyarıcılı programların çocukların büyüme ve gelişmesinde pozitif yönde etki ettiği görülmüştür (Alat, 2015, s. 481-495; Varol, 2015, s. 183-200). Kurumda kalan çocukların günlük yaşam programları, onların daha hareketli olmasına ve bir yetişkinle etkileşim içerisinde olmasına firsat tanınır şekilde düzenlendiğinde gelişimlerinin destekleneceği belirtilmektedir. Taneja, Beri ve Puliye (2004), araştırmalarında bir kurumda kalan 6 ay ve 3 yaş arasındaki tüm çocuklarla günde 90 dakika süren yapılandırılmış oyun planı üzerinde iki hafta çalıştıktan sonra kurumdaki çocukların motor ve zihinsel skorlarının 23 puan arttığını saptamışlardır. Benzer şekilde, Dragomir, Sparling, Ramey ve Florescu (2005), kurumda kalan bebeklerden oluşan bir gruba uyarıcı çevre programı uygulamış ve Denver Gelişim Testi ile ölçülen gelişim alanlarında önemli ölçüde iyileşmeler olduğunu gözlemlemiştir.

Çocuğun gelişiminin desteklenmesi için bir kurum çalışanıyla yakın iletişim kurması kurumda yetişmenin yaratabileceği bir takım olumsuz etkileri azaltmaktadır (Alat, 2015). Muhammedrahimov ve diğerleri (2004), kurumda kalan bebeklerin gelişimini desteklemek için onlara hem bakım personelleriyle süreklilik gösteren bir eğitim programı hem de bilişsel uyaran içeren etkinlik programı uygulamış ve sonuç olarak kurumun çevre koşullarının uyaran yönünden desteklendiğinde bebeklerin daha neşeli ve çevrelerine karşı ilgi düzeylerinin ve beceriyi gerçekleştirme oranlarının daha yüksek olduğunu bulmuşlardır. Özdemir, Sefer ve Türkdoğan (2008), kurumda yetişen çocuklarda gözlenen gelişim geriliklerini kurum ortamına, kurumların sağlayabildiği sınırlı bakıma ve özellikle yetersiz bilişsel uyarıma bağlamış, kurumların çocuklar üzerinde yarattığı etkilerin kısa süreli olduğunu ve erken müdahaleler ile bu etkilerin ortadan kalkacağını savunmuşlar ve çalışmalarında kurumda kalan çocukların gelişimlerini destekleyici bir proje uygulamışlardır. Sonuç olarak, yaşı ile uyumlu normal gelişim gösteren çocukların sayısında bir artış, anormal ve şüpheli gelişim gösteren çocukların sayısında bir azalma olduğu bulunmuştur. 
Mclean'a (2003) göre kurumlarda kalan çocukların öncelikli olarak, sağlık bakımı, hijyen ve beslenmeye odaklanılmakta, gelişimleri için uygun ortam hazırlanmasında yetersiz kalınmaktadır. Çocukların gelişim basamaklarına uygun becerileri kazanabilmesi için sunulan fırsatlar kısıtlı olduğunda, gelişim basamaklarında gecikmeler bulunabilir ancak bu gecikmeler, uygun ortamlar sağlandığında artış gösterecektir. Özellikle gelişimin ilk aşamalarında çocukların keşifleri, oyunları, sosyal aktiviteleri bilişsel süreçlerinin yanı sıra hareket becerilerinin de gelişimini sağlamaktadır.

İlgili literatürde, kurumda kalan çocuklarla yapılan çalışmalarda genel olarak kurumların çevre imkanlarının ve yapısal düzenlerinin gelişim üzerine olumsuz etkileri olduğu ve bu etkilerin uygun erken müdahale ve gelişim destek programları ile ortadan kaldırılabileceği ve kısa sürede kurum çocuklarının normal gelişim basamaklarını yakalayabileceği öne sürülmektedir. Kurumda kalan çocuklara yapılan çalışmalarda, erken dönemde çevreyi keşfetme firsatlarının tanınmasının gelişimi üst seviyelere çıkaracağından bahsedilmektedir. Özellikle küçük çocukların ve bebeklerin ihtiyacı olan bu keşif firsatlarının, yapılan çalışmalarla onlara sağlanması motor performanslarında bir artış sağladığı ve bunun bilişsel gelişimi de doğrudan etkilediği anlaşılmaktadır. Sonuç olarak, konu ile ilgili alan yazında yer alan araştırmaların bulguları ile bu çalışmanın bulguları, gelişime olumlu yönde katkı sağlaması sebebi ile benzerlik gösterdiği görülmektedir. Aşağıda Tablo 4'te çalışma grubundaki bebeklerin bulunduğu ay içerisinde gecikme ya da uyarı puanı aldığı maddeler gösterilmiştir.

Tablo 4

Denver IIGTT İnce Motor ve Kaba Motor Gelişim Alanlarında Gecikme ya da Uyarı Puanı Alındığı Saptanan Maddeler

BEBEKLERIN YASSLARI

\begin{tabular}{|c|c|c|c|c|c|c|c|c|c|}
\hline & $\begin{array}{l}\text { Denver IIGTT Motor } \\
\text { Gelişim Maddeleri }\end{array}$ & & ay & & 4 ay & & 5 ay & & 6 ay \\
\hline & & Uyar1 & Gecikme & Uyar1 & Gecikme & Uyar1 & Gecikme & Uyar1 & Gecikme \\
\hline \multirow{12}{*}{ İnce Motor } & $\begin{array}{l}\text { Orta Hatta Kadar } \\
\text { İzleme }\end{array}$ & & & & & & & & \\
\hline & $\begin{array}{l}\text { Orta Hattı Geçen } \\
\text { İzleme }\end{array}$ & & & & $\mathrm{X}$ & & & & \\
\hline & Ellerini Birleştirme & $\mathrm{X}$ & & $\mathrm{X}$ & & & & & \\
\hline & Çıngırağı Kavrama & & $\mathrm{X}$ & $\mathrm{X}$ & & & $X$ & & $X$ \\
\hline & Üzüme Bakma & $\mathrm{X}$ & & $\mathrm{X}$ & & $\mathrm{X}$ & & & $X$ \\
\hline & $180^{\circ}$ İzleme & $\mathrm{X}$ & & $\mathrm{X}$ & & & & & \\
\hline & $\begin{array}{l}\text { Yere Düşen Ponponu } \\
\text { Arama }\end{array}$ & & & $\mathrm{X}$ & & $\mathrm{X}$ & & $\mathrm{X}$ & \\
\hline & Nesneye Uzanma & & & $\mathrm{X}$ & & $\mathrm{X}$ & & $\mathrm{X}$ & \\
\hline & 2 Küp Alma & & & & & & & & $\mathrm{X}$ \\
\hline & Üzümü Cekerek Alma & & & & & & & $\mathrm{X}$ & \\
\hline & $\begin{array}{l}\text { Küpü Elden Ele } \\
\text { Geçirme }\end{array}$ & & & & & & & & \\
\hline & $\begin{array}{l}\text { Küpleri Birbirine } \\
\text { Vurma }\end{array}$ & & & & & & & $X$ & \\
\hline \multirow{7}{*}{$\begin{array}{l}\text { Kaba } \\
\text { Motor }\end{array}$} & Eşit Hareketler & & & & & & & & \\
\hline & $\begin{array}{l}\text { Yüzükoyun Başını } \\
\text { Kaldırma }\end{array}$ & & & & & & & & \\
\hline & Başını $45^{\circ}$ Kaldırma & & & & & & & & \\
\hline & Başı Dik Oturma & & & $\mathrm{X}$ & & & & & \\
\hline & $\begin{array}{l}\text { Otururken Başını } \\
\text { Düşürmeme }\end{array}$ & & & & $\mathrm{X}$ & & $\mathrm{X}$ & & \\
\hline & Başını $90^{\circ}$ kaldırma & & & $\mathrm{X}$ & & $\mathrm{X}$ & & & \\
\hline & $\begin{array}{l}\text { Kol Desteği ile } \\
\text { Göğsünü Kaldırma }\end{array}$ & & & & & & & & \\
\hline
\end{tabular}




\begin{tabular}{|c|c|c|c|c|c|}
\hline Dönme & $\mathrm{X}$ & $X$ & $\mathrm{X}$ & $\mathrm{X}$ & \\
\hline Desteksiz Oturma & & & $\mathrm{X}$ & $\mathrm{X}$ & $\mathrm{X}$ \\
\hline
\end{tabular}

Tablo 4'te bebeklerin bulundukları aya göre, ince motor gelişim ve kaba motor gelişim alanlarında uyarı ya da gecikme puanı aldıkları maddeler gösterilmektedir.

İnce motor gelişim alanında uyarı puanı alınan maddelerin sırasıyla,

- 3 aylik bebeklerde "ellerini birleştirme", "üzüme bakma", " $180^{\circ}$ izleme",

- 4 aylık bebeklerde "ellerini birleştirme", "çıngırağı kavrama", "üzüme bakma", "180 izleme", "yere düşen ponponu arama", "nesneye uzanma",

- 5 aylık bebeklerde "üzüme bakma", "yere düşen ponponu arama", "nesneye uzanma",

- 6 aylık bebeklerde "yere düşen ponponu arama", "nesneye uzanma", "üzümü çekerek alma", "küpleri birbirine vurma" maddeleri olduğu;

gecikme puanı alınan maddelerin ise sırasıyla,

- 3 aylık bebeklerde, "çıngırağı kavrama",

- 4 aylık bebeklerde, "orta hattı geçen izleme",

- 5 aylık bebeklerde, "çıngırağı kavrama",

- 6 aylık bebeklerde, "çıngırağı kavrama”, "üzüme bakma”, "2 küp alma” maddeleri olduğu görülmektedir.

Tablo 4'te kaba motor gelişim alanındaki duruma bakıldığında, bebeklerin bulundukları aya göre kaba motor gelişim alanında uyarı puanı aldığı maddelerin sırasıyla,

- 3 aylık bebeklerde uyarı puanı alınan madde olmadığı,

- 4 aylık bebeklerde "başı dik oturma", "başını $90^{\circ}$ kaldırma", "dönme",

- 5 aylık bebeklerde "başın $90^{\circ}$ kaldırma", "dönme", "desteksiz oturma",

- 6 aylık bebeklerde "dönme", "desteksiz oturma" maddeleri olduğu;

gecikme puanı alınan maddelerin ise sırasıly,

- 3 aylık bebeklerde gecikme puanı alınan madde olmadığ 1 ,

- 4 aylık bebeklerde, "otururken başını düşürmeme", "başını 90 kaldırma", "dönme",

- 5 aylık bebeklerde, "otururken başını düşürmeme",

- 6 aylık bebeklerde, "desteksiz oturma" maddeleri olduğu görülmektedir.

D2GTT puanlaması ve yorumlamasına göre, uyarı puanı alınan maddelerde, aynı yaş grubundaki bebeklerin \%25-\%75' inin maddelerdeki becerilerde yeterlilik kazanmış olduğu kabul edilir. Bu sebeple, değerlendirme yapılan bebeklerin bu becerilerde yeterlilik kazanması için zaman verilir ve bir süre sonra yeniden gelişim değerlendirmesi yapılarak becerinin kazanılıp kazanılmadığına bakılır. Eğer beceriler hala kazanılmamış ise gecikmiş gelişme olduğu düşünülür. Bu çalışmada, uyarı puanı alınan maddelerdeki becerilerin kazanılmış olması, bu durumun hem bebeklerin geçirdiği süreye bağl1 olgunlaşmadan, hem de uygulanan duyu eğitimi programından olduğu söylenebilir.

Ayrıca D2GTT puanlaması ve yorumlamasına göre, yaş çizgisi dahilinde bebeklerin kazanmış olması beklenilen maddeler vardır. Yaş çizgisinin tamamen altında kalan bir maddedeki beceriyi bebeğin kesinlikle kazanmış olması beklenir, aksi halde bu gecikme olarak tanımlanır. Buna göre, gecikme puanı alınan maddeleri içeren becerileri bebeklerin kazanmış olmasında yalnızca bebeklere uygulanan duyu eğitimi programının etkisinden söz etmek mümkündür.

$\mathrm{Bu}$ bilgilere göre, ince motor gelişim alandaki uyarı ve gecikme puanı alınan maddeler karşılaştırıldığında, ortak olan bazı maddeler olduğu görülmektedir. Bu bağlamda, bebeklerin kurum ortamlarında ince motor alandaki bu becerileri gerçekleştirmek için firsatları olmadığı, belirli becerileri keşfetme konusunda bebeklerin yetersiz kaldığ 1 söylenebilir. Örneğin "çıngırağı kavrama" ve "üzüme bakma" maddelerini içeren becerilerden bebeklerin hem gecikme hem de uyarı puanı aldıkları görülmektedir. Dolayısıyla, kurumdaki bebeklerin görsel ve dokunsal uyaran içeren materyal çeşitliliğine ve bu materyallerle vakit geçirmeye ve oynamaya daha fazla ihtiyacı olduğu yorumu yapılabilir.

Bilişsel becerileri geliştiren aktivelerin çoğu ince motor beceri kullanımını içerir. Bebekler ve çocuklar hareket yolu ile öğrenir, çevreleri ile hareket yolu ile etkileşime girerler ve çevreleri hakkındaki bilgilerini arttırırlar. Bu yolla çocuklar var olan bilgilerine yeni bilgiler ekleyerek bilişsel olarak da 
gelişim sağlarlar (Dragomir ve diğerleri 2005). İnce motor beceriler, daha iyi biliş ile ilgilidir ve ince motor gelişimin daha sonraki dönemlerdeki bilişsel ve davranışlar performansın temeli olduğu düşünülür (Smyke, Zeanah, Nelson ve Fox, 2003). Buna göre, kurumdaki çocukların ince motor becerilerini arttırıcı, ellerini ve parmaklarını kullanmayı içeren (farklı yapıda ve büyüklükte nesneleri eşleştirme, üst üste/yan yana dizme, şekil kovasından uygun büyüklükteki göze atma, yaş düzeyine uygun puzzle yapma, bir bütünün parçalarını bulmasını sağlama gibi) aktiviteler onların bilişsel gelişimine katkı sağlayacaktır.

Kaba motor gelişim alanında, uyarı ve gecikme puanı alınan maddeler karşılaştırıldığında, ortak olan bazı maddeler olduğu görülmektedir. Bu bağlamda, bebeklerin kurum ortamlarında bu becerileri gerçekleştirmek için firsatları olmadığ 1 , belirli becerileri keşfetme konusunda bebeklerin yetersiz kaldığı söylenebilir. Örneğin "dönme" ve "desteksiz oturma" maddelerini içeren becerilerden bebeklerin hem gecikme, hem de uyarı puanı aldıkları görülmektedir.

Yerçekimine karşı yapılan denge becerileri, daha iyi bir biliş ile ilgilidir (Özdemir ve diğerleri, 2008). Bireyin doğuştan yoksunluğu veya çevrenin yoksunluk etkileri algı ve eylem arasındaki ilişkiyi etkiler. Kurumda kalmanın duyusal-algısal sistemde etkili olduğu, kurumda çocuklar arasında yapılan çalışmalarda, kurumda kalmanın dokunma ve denge uyaranlarını içeren becerilerde daha düşük puanlar almaya sebep olduğu bulunmuştur (Maclean, 2003). Lin (2003), kurumda kalan 13 aylık bebeklerin hareket beceri puanlarının ailesi yanında kalan bebeklere oranla daha düşük bulmuştur. Morison ve diğerleri (1995), kurumda kalan çocukların kaba motor becerilerini \%59 oranında saptamış ve bu oranın, çocukların koruyucu aile yanına gittikten sonra \%91 seviyesini çıktığını tespit etmiştir. Ayrıca birçok araştırmacı, kurumdaki küçük bebeklerin temel gereksinimlerinin giderilmesi dışında çok az uyaran aldığını bildirmektedir. Bir bakım veren bir evde günde 7 ile 10 çocuğa hizmet verdiğinde her birine ayıracak çok az zaman kalmaktadır. Bu durumda bebekler çok az görsel ve işitsel uyaran alabilirler ve günlerinin çoğunu sırtüstü yatarak geçirmiş olurlar. Araştırmacılar, yoksun bebeklerin stereotipik yuvarlanma dışında kesinlikle hareketsiz olduğunu bulmuşlardır (Gander ve Gardiner, 2004, s. 139140). Bu bağlamda, alan yazındaki çalışmaların sonuçları ile bu çalışmada, kaba motor gelişim alanında, dönme ve desteksiz oturma gibi hareket formlarını içeren denge becerilerini bebeklerin henüz kazanamamış olma durumları benzerlik göstermektedir. Dolayısıyla, kurumdaki bebeklerin, denge becerilerini içeren hareketleri kazanması için farklı mekan ve konumlarda hareket becerilerini geliştirme firsatlarının yaratılmasına ihtiyacı olduğu söylenebilir.

\section{Sonuç ve Öneriler}

Sonuç olarak, bebeklerin ince ve kaba motor gelişim alanı ön test ve son test puanları arasında anlamlı bir değişiklik olduğu, $(\mathrm{p}<0,05)$ bulunmuştur. Çalışmada, motor gelişimin kısa sürede daha gözlemlenebilir olması sebebi ile gelişim tek bir boyutta ele alınmış olsa da, erken dönemdeki motor hareketin öğrenme üzerindeki etkisi, çalışmanın ilerlemesinin açı bir şekilde ortaya konmasına firsat vermiştir. Duyu eğitimi programı uygulamaları sırasında, bebeklerin var olan gelişim durumu ile program ilerledikçe bebeklerin gelişiminin geldiği noktanın gözlemlenmesi ve karşılaştırılması, bebeklerin hangi becerilerde desteğe ihtiyacı olduğunu ortaya koymuştur.

Araştırma kapsamında elde edilen sonuçlara yönelik araştırmacılara ve sosyal hizmet alanında çalışan personele öneriler şu şekildedir:

- Kurumlardaki bebek evlerinin çevre düzenlemesine önem verilmeli, bebeklerin gün içerisinde daha hareketli olmalarına ve çevreyi keşfetmelerine firsat verilmelidir. Kurumların yapısal ve çevresel düzenlemelerini içeren yurt dışında uygulanmış programları uyarlama çalışmaları yapilabilir.

- Bebeklerin, günlük yaşamlarındaki duyu-motor hareketin, motor gelişime faydalarının yanında, bilişsel faydalarının da farkında olmak gerekir. Korunmaya muhtaç çocuklar için özel olarak hazırlanmış eğitim programları hazırlanabilir ve çocukların birbirleriyle ve kendilerinden sorumlu olan yetişkinlerle etkileşimlerini geliştirmelerine yardımcı olunabilir. Bu programların Aile, Çalışma ve Sosyal Hizmetler Bakanlığı tarafından alanında uzman kişilerce hazırlanması ve tüm ülke genelinde Bakanlığa bağlı kuruluşlarda yaygınlaştırılması için çalışmalar yapilabilir.

- Ülkemizde, kurumlarda kalan çocuklarla yapılan araştırmaların sayısı oldukça azdır. Bu nedenle bu kurumlarda yapılacak araştırmalarda, çocukların bireysel gereksinimlerine yönelik bütünsel gelişimini kapsayıcı erken müdahale programları hazırlanabilir ve uygulanabilir. 


\section{Etik Kurul Onay Bilgileri}

Çalışmaya başlamadan önce "Etik Kurul Onayı" Gazi Üniversitesi Etik Komisyonunun 30.12.2016/15 tarih/sayılı raporu ile alınmış olup, çalışmanın Karşıyaka Çocuk Evleri Sitesi Müdürlüğünde yapılabilmesi için Aile Çalışma ve Sosyal Hizmetler Bakanlığı Eğitim ve Yayın Dairesi Başkanlığının 05.04.2017 tarih ve 38558 sayılı Müsteşarlık Oluru ile gerekli onaylar alınmıştır.

\section{Kaynaklar}

Aksoy, B. ve Çiftçi, A. H. (2008). Erken çocukluk döneminde gelişimi destekleyen oyunlar. Ankara: Pegem.

Aksoy, B. ve Koran, A. N. (2016). Türkiye'de bebeklik dönemi ile ilgili yapılan araştırmaların analizi (2004-2014). Türkiye Sosyal Araştırmalar Dergisi, Ağustos, 363-376.

Alat, Z. (2015). Çocuklara sağlıklı ve zinde olmayı öğretme: fiziksel gelişim ve sağlık. H. Z. İnan ve T. İnan, (Yay. haz.). Erken Çocukluk Ë̆itiminde Etkili Uygulamalar içinde (ss. 481-495). Ankara: Nobel.

Anadolu Üniversitesi (2014). 0-36 aylık gelişimi risk altındaki çocuklar için gelişim destek programı $(G E D E P)$. Erişim adresi: http://eae.anadolu.edu.tr/assets/yazili/20140823145747_ksun.pdf

Aral, N. ve Yücelyiğit, S. (2014). Bebeklerde algı. D. Sevimay-Özer ve A. Aktop (Yay. haz.) Motor gelişimi anlamak: bebekler, çocuklar, ergenler, yetişkinler içinde (ss. 154-166). Ankara: Nobel.

Bayhan, P. ve Artan, İ. (2009). Çocuk gelişimi ve eğitimi. İstanbul: Morpa.

Berk, L. (2015). Bebekler ve çocuklar (N. Işıkoğlu-Erdoğan, Çev. Ed.). Ankara: Nobel.

Büyüköztürk, Ş. (2014). Bilimsel araştırma yöntemleri. Ankara: Pegem.

Dragomir, C., Sparling, J., Ramey, L. S. ve Florescu, L. (2005). An educational intervention improves developmental progress of young children in a Romanian orphanage. Infant Mental Health Journal, 26(2), 127-142.

Ellison, S. (2016). Akıllı çocukların oynadıkları 365 oyun (P. Akkaş, Çev.). İstanbul: Pozitif.

Featherstone, S. ve Featherstone, P. (2015). 0-20 ay bebeklerle yapllacak 50 eğitici aktivite (T. Kanbur, Çev.). İstanbul: Aktif.

Gander, J. M. ve Gardiner, W. H. (2004). Çocuk ve ergen gelişimi (A. Dönmez, N. Çelen ve B. Onur, Çev.). Ankara: İmge.

Krog, S. (2015). Movement activities: A critical link in developing motor skills and learning in early childhood. African Journal for Physical, Health Education, Recreation and Dance (AJPHERD, 21(1:2), 426-443.

Lin, S. H. (2003). Sensory integration, growth, and emotional and behavioral regulation in adopted post-ınstıtutıonalized children (Doctoral dissertation). Erişim adresi: http://www.mkutup.gov.tr/

Maclean, K. (2003), The impact institutionalization on child development. Development and Psychopayhology, 15(4), 853-884.

Milli Eğitim Bakanlığı (t.y.). 0-36 aylık çocuklar için etkinlik kitabı. Erişsim adresi: http://tegm.meb.gov.tr

Milli Eğitim Bakanlığı (t.y.). 0-36 Ay Çocuklar İçin Eğitim Programı ile Bütünleştirilmiş Aile Destek Eğitim Rehberi (EBADER). Erişim adresi: http://tegm.meb.gov.tr/dosya/okuloncesi/036ebaderegitimcikitap.pdf

Morison, S. J., Ames, E. W., Chisholm, K. ve Carter, M. C. (1995). The development of children adopted from Romanian orphanages. Merrill-Palmer Quarterly, 41(4), 411-430.

Muhamedrahimov, J. R., Palmov, O., Nikiforova, V. N., Groark, J. C. ve McCall, B. R. (2004). Institution-based early intervention program. Infant Mental Health Journal, 25(5), 397-507.

Özdemir, N., Sefer, N. ve Türkdoğan, D. (2008). Bir sosyal sorumluluk projesi örneği: 'korumaya muhtaç çocuklar'. Cumhuriyet Üniversitesi Sosyal Bilimler Dergisi, 32(2), 285-305.

Sloutsky, M. V. (1997). Institutional care developmental outcames of 6 and 7 year old children: a contextualist perspective. International Journal of Behavioral Development, 20(1), 131-151.

Smyke, A., Zeanah, C., Nelson, C. ve Fox, N. (2003). Designing research to study the effects of institutionalization on brain and behavioral developmant. Development and Psychopathology, 15(4), 885-907.

Taneja, V., Beri, R. S. ve Puliye, J. M. (2004). Play in orphanages. The Indian Journal of Pediatrics, 71(4), 297-299. 
Turan, F. ve İpek-Yükselen, A. (Yay. haz.). (2015). Çocuk gelişimi 1: bebeklik döneminde gelişim. Ankara: Hedef.

Varol, F. (2015) Bebeklik ve yürüme çağında fiziksel gelişim. N. Işıkoğlu-Erdoğan (Yay. Haz.), Bebekler ve Çocuklar içinde (ss.183-200). Ankara: Nobel.

Yalaz, K., Anlar, B. ve Bayoğlu, B. (2009). Denver II gelişimsel tarama testi. "Türk çocukları standardizasyonu". Ankara: Gelişimsel Çocuk Nörolojisi.

Young, C. (2010). Bebekler ve yürüme çağındaki çocuklar için eğlendirici ve eğitici etkinlikler (H. Doğan, Çev.). Ankara: Fersa.

\section{Extended Abstract \\ Introduction}

This research is carried on to analyze the effect of 'Sensory Education Program' on motor development of infants in need of legal protection. In early childhood, the contribution of family and mutual interaction with caregiver is increasingly emphasized. However, when families aren't stimuli or supportive, there might be retardation in developmental stages.

Accordingly, the gained data from this study have importance because they statistically show the situation of infants in need of legal protection in our country and contribute to take action in making changes for them. Besides, these data are crucial for showing that early motor behaviours play an important role in their development and contribute in their cognitive development.

\section{Method}

In this research, single screening model, one of general screening models, was used and pretest-posttest single group design which is an experimental screening design was implemented. The target population of the study is composed of 12 infants at the age of 3-6 months who live in Child Homes attached to Izmir Provincial Directorate of Family and Social Policies. In this research, 'Sensory Education Program' was implemented 3 times a week during 16 weeks for the target population of the study. In this program, 'Development Support Program for Aged 0-36 Months Children at Risk (GEDEP)' which is prepared by the teaching staff of Anadolu University Faculty of Education within the scope of 'Lifelong Learning Program' of European Union, and 'Family Support Training Guide Integrated with Education Program for Children Aged 0-36 Months (EBADER)' were taken into consideration. Also, activities were prepared within the context of development indicators in fine and gross motor skills of children aged 0 12 months. The program consists of 25 activities which support elected learning outcomes and indicators. While choosing activities, activity books for that age group were used in order to attract children's attention. The documents that provide data for the research are Personal Information Form and The Denver II Developmental Screening Test.

The program lasted for 3 months in total and children were evaluated for 4 times at regular intervals by using Denver II Developmetal Screening Test. Infants' deveopment levels were shown in tables in the study.

\section{Findings and Results}

Children's development stages were evaluated by using the assesments gained from the implementation of Sensory Education Program, and findings were revealed with tables and graphics. In addition, The Statistical Program for Social Studies 20 package program was used to analyze the gained data, and it is determined that tha data don't follow normal distribution. Wilcoxon Signed Ranks Test was used to make intra-group comparisons, and as a result, it is confirmed that there is a significant difference $(p<0,05)$ between the pre-test and post-test averages of fine and gross motor skills and that development of infants in Child Homes shows a progress from suspicious development towards normal development. According to the pre-test results, it is found out that the development of $50 \%$ of the study group is suspicious; however, after the implementation of sensory education program, the post-test results showed that this rate decreased and became $8,4 \%$.

In the assesments, infants had warning or delay points in skills like 'grasp the rattle' and 'look at the grapes' which are fine motor skills. Therefore, it can be said that infants in Child Homes need to have a variety of visual and tactual materials and to play with these materials longer. Fine motor skills are related to better cognition and it is thought that fine motor development is crucial for cognitive and 
behavioural performance in later stages. Accordingly, if the infants in Child Homes do more activities which make them use their hands and fingers much, it will contribute to their cognitive development.

In the gross motor development area, considering the items in which infants got warning and delay points, it is seen that infants got these points in skills like 'turn around' and 'sit up alone' movements. Balance skills against gravity require better cognition, so, the state of being deprived by birth or environmental effects causing deprivation affect the relationship between perception and action. In the studies carried out on children in Child Homes, it is seen that staying in Child Homes has affected sensory and perceptual systems and that the infants in Child Homes have got low points in tactual and balance skills compared to others. When a caregiver look after 7 to 10 children in a Child Home, he/she will have a short time for each child. In this case, babies can get less audio-visual stimuli and they spend most of their time by laying back. On the other hand, researchers found out that deprived babies are inactive apart from stereotyped rolling. In this context, infants' state of not obtaining balance skills like turning and sitting up alone which are gross motor skills shows similarity with the results of other studies in this field. Therefore, it can be said that it is necessary to create opportunities to make infants in Child Homes learn balance movements. 